\title{
Carotid Artery Ultrasound for Syncope
}

\author{
Philip C. Dittmar, MD*, Leonard S. Feldman, MD²
}

${ }^{1}$ Department of Medicine, University of Maryland School of Medicine, Baltimore, Maryland; ${ }^{2}$ Department of Medicine, Johns Hopkins University School of Medicine, Baltimore, Maryland.

The "Things We Do for No Reason" (TWDFNR) series reviews practices which have become common parts of hospital care but which may provide little value to our patients. Practices reviewed in the TWDFNR series do not represent "black and white" conclusions or clinical practice standards, but are meant as a starting place for research and active discussions among hospitalists and patients. We invite you to be part of that discussion.

\section{CASE PRESENTATION}

A 66-year-old man with a history of hypertension is hospitalized for a transient loss of consciousness while shopping at a farmers market with his wife on a hot summer day. He recalls feeling lightheaded seconds before he lost consciousness. He had no chest pain, diaphoresis, dyspnea, shaking movements, slurred speech, or head trauma. He felt mildly fatigued following the episode, but has since returned to his baseline. Physical examination, including a thorough cardiac and neurological examination, is normal. The hospitalist ponders whether to order a carotid artery ultrasound as part of a syncope evaluation.

\section{BRIEF OVERVIEW}

Syncope is defined as a rapid onset loss of consciousness of short duration as a result of global cerebral hypoperfusion with loss of postural tone, which is followed by spontaneous and complete recovery. ${ }^{1}$ This definition describes syncope as a symptom rather than a disease. The challenge for providers is to determine the etiology of the syncope along with its attendant risk of morbidity and mortality. Given the wide variety of etiologies and concern over potentially missing an important etiology, diagnostic testing can become elaborate, expensive, and frequently low yield.

In the adult population, it is believed that approximately $35 \%$ of individuals will experience a syncopal episode in their lifetime. ${ }^{2}$ As a result, syncope

*Address for correspondence and reprint requests: Philip C. Dittmar, MD, University of Maryland Medical Center, 22 South Greene Street, Rm N13W46, Baltimore, MD 21201; Telephone: 410-328-2882;

Fax: 410-328-2977; E-mail: pdittmar@medicine.umaryland.edu

Additional Supporting Information may be found in the online version of this article.

Received: April 9, 2015; Revised: June 1, 2015; Accepted: June 27, 2015

2015 Society of Hospital Medicine DOI 10.1002/jhm.2428

Published online in Wiley Online Library (Wileyonlinelibrary.com). accounts for $1 \%$ to $3 \%$ of all emergency department visits and $1 \%$ to $6 \%$ of hospital admissions from emergency departments in the United States., ${ }^{3,4}$ The incidence and rate of hospitalization increase with age, as does the risk of mortality. ${ }^{5,6}$ There are 3 main types of syncope: cardiac, neurocardiogenic (vasovagal), and orthostatic. The presence of associated signs or symptoms with the syncope helps to differentiate the type and complexity of the syncope, while helping guide the diagnostic evaluation. Simple syncope is defined as the absence of focal neurological deficits or other signs or symptoms suggestive of transient ischemic attack (TIA) or cerebrovascular accident (CVA). ${ }^{7}$ A differential diagnosis for a transient loss of consciousness that includes TIA and CVA will prompt a very different evaluation.

\section{WHY YOU MIGHT THINK ORDERING CAROTID ARTERY ULTRASOUNDS FOR SYNCOPE EVALUATION ARE HELPFUL}

Carotid artery ultrasounds are used to assess the extracranial carotid arteries for the presence of stenosis and to determine the direction of blood flow. The use of carotid artery ultrasound as a diagnostic tool in the evaluation of syncope can be traced to multiple articles from the 1980s. These articles noted the utility of screening patients with dizziness, lightheadedness, or syncope using carotid artery ultrasound due to possible decreased flow in the carotid artery circulation affecting cerebral perfusion. ${ }^{8,9}$ An association was noted between these symptoms and the presence of carotid artery stenosis. Further, a 1997 position paper from the American College of Physicians recommended that carotid artery or transcranial ultrasonography be reserved for syncope patients with carotid artery bruits or a history of neurovascular signs or symptoms. ${ }^{10}$ More recent studies reveal carotid artery ultrasounds are still being performed regularly in syncope patients. In 2 studies evaluating syncope in the elderly, approximately $13 \%$ to $16 \%$ of syncope patients had a carotid artery ultrasound performed in an effort to identify an etiology. ${ }^{7,11}$

Additionally, practitioners sometimes choose to perform carotid artery ultrasound in the evaluation of carotid sinus hypersensitivity. The carotid artery ultrasound can assess for the presence of stenosis or atheroma prior to performing carotid sinus massage, although the rate of persistent neurological complications from carotid sinus massage is estimated to occur in $1: 1000$ patients. $^{12}$ 


\section{WHY THERE IS "NO REASON" TO ORDER CAROTID ARTERY ULTRASOUNDS FOR THE EVALUATION OF SIMPLE SYNCOPE}

Carotid artery ultrasounds are unlikely to determine the etiology of the syncope. We should expect a highvalue test to reveal an etiology for the syncope episodes at a significant rate. In the 2009 study by Mendu et al. at Yale-New Haven Hospital, 267 ultrasounds were performed on 2106 syncope admissions of high-risk elderly patients (1920 total patients). ${ }^{11}$ Of the 267 ultrasounds, only 2 of the tests $(0.8 \%)$ helped to determine an etiology. Although $46 \%$ of the ultrasounds had abnormal findings, the measuring stick for these studies should be whether they uncover the etiology for syncope, not whether they find other unrelated vascular disease. In contrast, performing postural blood pressures helped to determine an etiology $15 \%$ to $21 \%$ of the time, depending on the criteria used to define an abnormal drop in postural blood pressures.

Similarly, in the 2005 study by Schnipper et al. at Massachusetts General Hospital, only 140 of 4199 adult patients $(3.3 \%)$ who presented as either inpatients or outpatients for syncope or presyncope were referred for neurovascular testing. ${ }^{13}$ Carotid artery ultrasound was performed in 109 of these patients, and the study neurologist could invoke cerebrovascular lesions as potential factors for syncope in only 2 patients, both of whom had syncope and focal neurologic symptoms. Moreover, both of the patients had severe cardiovascular disease (severe ischemic cardiomyopathy with complete heart block following coronary bypass surgery in 1 and aortic stenosis with decreased left ventricular ejection fraction in the other). It is quite possible that the ultrasounds did not find the etiology for any of the 140 high-risk patients with syncope in the study.

In addition, the 2014 study by Scott et al. at Brigham and Women's Hospital analyzed carotid artery duplex ultrasounds performed on 313 inpatients and outpatients with syncope over a 5-year period, excluding those with focal neurological deficits or carotid bruits. ${ }^{7}$ Although 48 of the 313 patients $(15.4 \%)$ were diagnosed with carotid stenosis of greater than $50 \%$, the carotid artery ultrasound did not reveal a causal diagnosis in any patients. On the other hand, 7 patients had a change in medical management, and 1 patient underwent carotid endarterectomy following the carotid artery ultrasound, which was incidental to what prompted the evaluation.

Mendu et al. calculated the cost per test affecting the diagnosis or management of syncope (although diagnosis is the only important parameter). The cost per test was calculated as the charge per test multiplied by the cost-tocharge ratio of 0.34 , based on the 2007 Yale-New Haven Hospital cost-to-charge ratio. ${ }^{11}$ For carotid artery ultrasound, the cost per test was $\$ 19,580$ to affect diagnosis or management as compared to $\$ 23$ to $\$ 33$ for postural blood pressures. Combining these findings with the results from the Schnipper et al. and Scott et al. articles, where carotid artery ultrasounds may not have found the cause of syncope in any of the patients, it seems clear that obtaining a carotid artery ultrasound in the evaluation of simple syncope is a low-value proposition.

Many low-value tests, like carotid artery ultrasounds, suffer from both upfront costs, as calculated in the Mendu et al. study, and downstream costs triggered by the testing itself. Performing carotid artery ultrasounds in elderly high-risk syncope populations is likely to reveal asymptomatic carotid artery vascular disease, which may lead to more unwarranted testing or treatments in light of the initial indication for the test. In the Mendu et al. article, 122 (46\%) of the 267 carotid artery ultrasounds performed on elderly patients admitted with syncope were abnormal. Abnormal findings were defined as "any abnormality that was not seen on prior testing as written in the test reports." Similarly, Schnipper et al. found that $40 \%$ of the 140 highly selected patients had mild-tosevere carotid vascular disease.

National guideline recommendations are aligned with these findings. The National Institute for Health and Clinical Excellence Guideline for the Management of Transient Loss of Consciousness does not include carotid artery ultrasound in the summary of clinical recommendations. ${ }^{14}$ Furthermore, the American Academy of Neurology Choosing Wisely campaign's recommendation 2 is: Do not perform imaging of the carotid arteries for simple syncope without other neurologic symptoms. ${ }^{15}$

\section{WHAT YOU SHOULD DO INSTEAD: CHECK POSTURAL BLOOD PRESSURES}

As is true for most of medicine, greater focus should be paid to the history and physical examination during the initial evaluation of the patient with syncope. Take great care to determine which patients have a history or symptoms concerning for neurologic or cardiac etiologies. Use this information to guide further diagnostic testing. Additionally, orthostatic testing is too often overlooked as an important diagnostic study. As described in the Mendu et al. study, orthostatic testing is inexpensive and effective, helping to determine an etiology $15 \%$ to $21 \%$ of the time. Carotid artery ultrasounds should be reserved for those patients with transient or permanent focal neurological symptoms.

\section{RECOMMENDATIONS}

1. In patients suspected of syncope in the absence of other neurologic symptoms, carotid artery ultrasound should not be included in the diagnostic evaluation.

2. Utilize postural blood pressures in the initial evaluation of syncope as an inexpensive and high-value component of the physical examination.

3. For patients with acute neurological findings in the setting of possible syncope, evaluate the patient for stroke. 
4. Use the history and physical examination to guide further evaluation.

\section{CONCLUSION}

Carotid artery ultrasounds should not be used to evaluate the cause of syncope in an effort to find incident symptomatic carotid vascular disease. Carotid artery ultrasounds rarely help determine the etiology of the syncopal episode and are more likely to find asymptomatic carotid vascular disease in the elderly population. The identification of carotid vascular disease can lead to further inappropriate testing and treatments unrelated to the indication for testing.

Disclosure: Nothing to report.

Do you think this is a low-value practice? Is this truly a "Thing We Do for No Reason?" Share what you do in your practice and join in the conversation online by retweeting it on Twitter (\#TWDFNR) and liking it on Facebook. We invite you to propose ideas for other "Things We Do for No Reason" topics by emailing TWDFNR@hospitalmedicine.org.

\section{References}

1. Kapoor, WN. Syncope. N Engl J Med. 2000;313(25):1856-1862.

2. Ganzeboom KS, Mairuhu G, Reitsma JB, Linzer M, Wieeling W, va Dijk N. Lifetime cumulative incidence of syncope in the general population: a study of 549 Dutch subjects aged 35-60 years. J Cardiovasc Electrophysiol. 2006;17(11):1172-1176.
3. Kapoor WN. Evaluation and management of patients with syncope. JAMA. 1992;268(18):2553-2560.

4. Sun BC, Emond JA, Camargo CA Jr. Characteristics and admission patterns of patients presenting with syncope to U.S. emergency departments, 1992 to 2000. Acad Emerg Med. 2004;11:1029-1034.

5. Parry SW, Tan MP. An approach to the evaluation and management of syncope in adults. BMJ. 2010;340:c880.

6. Soteriades ES, Evans JC, Larson MG, et al. Incidence and prognosis of syncope. N Engl J Med. 2002;347(12):878-885.

7. Scott JW, Schwartz AL, Gates JD, Gerhard-Herman M, Havens JM. Choosing wisely for syncope: low-value carotid ultrasound use. J Am Heart Assoc. 2014;3(4):e001063.

8. Weinberger J, Biscarra V, Weisberg MK. Hemodynamics of the carotid-artery circulation in the elderly "dizzy" patient. J Am Geriatr Soc. 1981;29(9):402-406.

9. Weinberger J. Clinical applications of noninvasive carotid artery testing. J Am Coll Cardiol. 1985;5(1):137-148.

10. Linzer M, Yang EH, Estes NA III, Wang P, Vorperian VR, Kapoor WN. Diagnosing syncope. Part 2: unexplained syncope. Clinical efficacy assessment project of the American College of Physicians. Ann Intern Med. 1997;127(1):76-86.

11. Mendu ML, McAvay G, Lampert R, Stoehr J, Tinetti ME. Yield of diagnostic tests in evaluating syncopal episodes in older patients. Arch Intern Med. 2009;169(14):1299-1305.

12. Richardson DA, Bexton R, Shaw FE, Steen N, Bond J, Kenny RA. Complications of carotid sinus massage-a prospective series of older patients. Age Ageing. 2000;29(5):413-417.

13. Schnipper JL, Ackerman RH, Krier JB, Honour M. Diagnostic yield and utility of neurovascular ultrasonography in the evaluation of patients with syncope. Mayo Clin Proc. 2005;80(4):480-488.

14. Westby M, Davis S, Bullock I, et al. Transient Loss of Consciousness ('Blackouts') Management in Adults and Young People. NICE Clinical Guidelines, No. 109. London, UK: National Clinical Guideline Centre for Acute and Chronic Conditions, Royal College of Physicians; 2010.

15. Langer-Gould AM, Anderson WE, Armstrong MJ, et al. The American Academy of Neurology's top five choosing wisely recommendations. Neurology. 2013;81(11):1004-1011. 